\title{
The care-givers of patients with persistent vegetative state have a terrible life: the result of a qualitative study
}

Ehsan Alimohammadi

Kermanshah University of Medical Sciences

\section{Atefeh Arast}

Kermanshah University of Medical Sciences

\section{Alireza Abdi (D A_abdi61@yahoo.com )}

kermanshah university of medical sciences https://orcid.org/0000-0002-3184-2564

\section{Research}

Keywords: Traumatic brain injury, vegetative state, qualitative study

Posted Date: February 10th, 2020

DOI: https://doi.org/10.21203/rs.2.23025/v1

License: (c) (1) This work is licensed under a Creative Commons Attribution 4.0 International License.

Read Full License 


\section{Abstract}

Background persistent vegetative state (PVS) is one of the results of traumatic brain injury. These patients are hospitalized for a long time, and need more cares. The caregivers are first members who provide care and have some challenges accordingly. With regards to a lack of information in this issue, the current study was conducted to explore Iranian care-givers experiences of caring for PVS patients following traumatic brain injury.

Methods this study was conducted as a descriptive phenomenological study in 2019. Semi- structured interviews were done on caregivers of PVS in a center of trauma in Iran. The interviews were recorded and wrote verbatim, then analyzed using seven steps of Collazi with management of MAXQUDA software. Guba and Lincoln`s criteria were used in favor of rigor, including credibility, dependability, transferability, and confirmability.

Results twelve people participated in the study and five themes, and ten subthemes extracted from 428 codes. The themes were "falling into tensions", "seeking peace", "imposed therapeutic duties", "preserve connection" and 'unheard sounds".

Conclusion In this study, the caregivers of PVS experienced some injuries and familial crises. They wished peace by praying and drain their feelings, also did some imposed duties, and tried to address all the needs of patient. They assessed patients' signs daily and some information gap, therefore, wanted to obtain them by relationship with staff. The caregivers communicated with patients and hoped to recovery of patients. They were complained of accommodations and lack of staff visits.

\section{Background}

Traumatic brain injury (TBI) is the main reason of death and disability in people under 45 years. It is estimated more than 1.5 million people affected by TBI in the US, with incidence 295 per 100000 people, globally (1). Some research approved that TBI in developing countries has more disability and mortality, and patients with severe TBI (GCS < 8 ) have more mortality (2). In Iran, TBI, affected individuals less than 30 years and the common cause is car accident (3).

Approximately, $2.77 \%$ of patients with TBI are becoming "persistent vegetative state" (PVS). This statistic is higher in developing countries by $6.3 \%$ (4). The term of "vegetative" first mentioned by Aristotle's treatise On the Soul, and it was invented as a diagnosis in 1972 by Jennett and Plum(5). Vegetative state is a devastating condition, in which the patients may be awake but have no signs of awareness and recently is known as "unresponsive wakefulness syndrome"(6). In this state, the sleep-wake cycle and autonomic functions remain intact, but the awareness about self, others and environment would be lost(5). The criteria for diagnosis of PVS are usually subjective and recently, some imaging studies have been promoted (7). Meanwhile, there are some criteria for PVS, including; no evidence of awareness and relationship with environment, no response to stimuli and doing directed behavior, lack of language understanding, return of the sleep cycle, smiling, and yawning, and sufficient autonomic function to 
survive (by medical and nursing care); bowel and bladder incontinence and variability in cranial and spinal reflexes(8).

With regard to the criteria of PVS(8), these patients need strict and vigilant therapeutic and care. In a review study by Georgiopoulos et al. (2010), PVS patients treated by some medications such as levodopa, Amantadin, Zolapidem, and some surgical interventions, e.g. deep-brain stimulation, extradural cortical stimulation, and intrathecal baclofen (9). Another study showed that these patients require deliberate managements and care in domains of social, economic and ethical dilemmas, as well as nursing and medical actions. They are fully dependent to the nursing and caregivers and need to vigilant assessment due to the possibility of critical threatened issues(10). Furthermore, some clinical staff and physicians believe that PVS patient has no optimistic prognosis and advised to organ donation and euthanasia(11). However, these decisions are context-based with no allowance in Iran(12).

Given the latency in recovery and partly poor prognosis of PVS after $\mathrm{TBI}(13)$, the caregivers of PVS patients are considered as one of the main members of the therapeutic team. They are first resource of care, especially for patients with long-term and permanent needs(14). The caregivers experience a variety of distresses, prolonged grief, depressive symptoms, physical and financial burden, and social problems(15). This situation is much worser in Iran, due to some resource limitations in health care settings(16), and staff shortage (16), hence, the caregivers of PVS need support and help(17).The studies mostly focused on the care-giving challenges of PVS at home(18;19), and there is a lack of studies on this issue in hospitals. With regard to a shortage in data on care-giving of PVS patients following TBI, in the hospitals of Iran, the current study was conducted to explore the Iranian care-givers experiences of caring for persistent vegetative state patients, following traumatic brain injury.

\section{Methods}

This qualitative study was done as a descriptive phenomenological study in Jun -October 2019. these types of studies had emanated for extracting experiences of individuals and showing an essence of a reality in view of those experienced it (20). We used descriptive phenomenology research, because it was originated of Husserl philosophy and showed the lived experiences of participants with suspending the researcher viewpoints (21), that congruent with philosophical viewpoint of the researcher.

The setting of the study was intensive care unit and neurosurgery wards of Taleghani hospital of Kermanshah, the main trauma center of west of Iran. It is a governmental hospital with 200 active beds and saturation rate of $96-100 \%$. The participants were the family members of PVS patients, who were in the hospitals and cared for patients at least for one month and consented to participate in the study. They enrolled as purposive sampling, which is the common in qualitative researches for recruiting wellinformed people about a phenomenon(22).

For data collection, after taking the permission from research and technology deputy of Kermanshah University of medical sciences and identify the patients by introducing and diagnosing by first author who is expert in neurosurgery, the researcher (second and third authors) attended to the mentioned wards 
in the hospital and explained the aim and purposes of the study to the caregivers. After signing a writteninformed consent, a semi-structured interview was conducted by asking some open questions such as, "What are your experiences about care-giving?" "What are your challenges of care-giving?" And probing words, e.g. "why", "explain more", and "give an example". The interviews lasted about 18-43 minutes. They were performed in physician office in the ward, after agreement of participants. Data collection was continued until saturation. This term meaning no newer data and information and further data collection is unnecessary(23).

The interviews were tap-recorded and after each one, it was analyzed using seven-steps of Collazi approach that noted in the Morrow (2015) study(24). In first step, the researcher listened the audio files several times and read them after writing verbatim. In second step, the meaningful statements related to caregivers of PVS patient were determined. In third step, the researcher formulated the meanings, in this way, a related code was dedicated to each significant statement, it is notable, the researcher tried to bracket the opinions and presupposition about caring of PVS patients in this stage. In step four, the themes were emerged and clustered based on the meanings/codes. Furthermore, the themes were incorporated into each other and raised an exhaustive description of them in fifth step. In sixth step, we tried to structure the phenomenon of care-giving for PVS patients in the hospital, with offering participants quotations. In final step, the verification and trustworthiness of the structure and findings were implemented. MAXQUDA 10 software was used for data management.

The Trustworthiness was done with regard to four components of Guba and Lincoln`s criteria involving credibility, dependability, transferability, and confirmability that cited by Shenten (2004)(25). For credibility, the researcher fully engaged with the participants and immersed in their context and explained completely the purposes of the study and tried to provide an honesty space. At least two sessions were prepared between researchers, and the process of the study was discussed and the peer debriefing was done continually. Member check was performed by requesting the participants to have an opinion about the analyzed data. We tried to take all the meaningful statements into account, including negative statements and made a thick description about the findings. For transferability, all data about the settings of the study was provided. Dependability was addressed by explaining a clear description of methodological approach to repetition of study to other studies. For confirmability, we used note taking, and having a complete description for external audit, and the themes and subthemes have raised in clear district method.

\section{Results}

In this study, twelve participants, who were the main care-givers of a PVS patient, recruited to the study. Table 1 summarized the demographic characteristics of them.

After qualitative data analysis on 12 interview manuscripts, 428 codes were extracted, of them five themes of "falling into tensions", "seeking peace", "imposed therapeutic duties", "preserve connection", and "Unheard sounds", and ten subthemes were emerged (table 2). 


\section{Falling into tensions}

About 140 codes were related to this issue, and the caregivers expressed the tensions that happened after the event, in this regard, two subcategories including "caregiver injuries" and "familial crises" have been emerged.

\section{Caregiver injuries}

Most of the caregivers said that they getting a psychological shock when faced with injured patients. This was accompany with faint, dizziness, continuing crying and moaning. For example one of the caregivers that was the mother of patient said "while I see the head of my son that was splinted, I was so upset and hurt and I fall into my daughter's arms" (P12). Another participant said "I get a lot of ups and downs. I am very upset and shocked and feel asleep and not awake. It is a terrible nightmare" (P11). The participant 8 descried that moment as "The whole world crashed on my head".

Some caregivers took a physical damage because of inappropriate situation in the ward and they got malnourished and sleep disorders. Participant three declared about the bad status of sleeping beside the patient and said "I lay on the floor mosaics (which they barely allow) as the catheters are next to my face and the smell of urine is very disturbing", another caregiver explained her situation as "I have been starved for a long time; we have no place to stay and I have a cold and our situation is very bad" (P7).

\section{Familial crisis}

After happening the event, most of caregivers were confronted with some familial crises and 91 codes were extracted in this regards. Some participants such as P2 and P12, who were nephew and mother, and the patients were male, said that "the patients wives have divorced after accident", so because of this, other family members engaged in caring. P12 declared "At night I and my other son are (in hospital), and at days my granddaughter and $\mathrm{I}$, if have no school.... Everyone is upset and my son has no life, he is at work for days and is in hospital at night and (he is) tired". Another crisis for the families was economic problems, in which mostly announced that they cannot pay hospital charge and prepare the medications and devices. P11 was unemployed and said "My father has passed away for a year and we are all unemployed and we only receive my father's social security and we are financially under pressure, even, it is difficult for us to travel". Other participant who was the mother of patient also explained "I don't have enough money to get the supplies, and I am under the auspices of the Relief Committee, and they give me little salaries, they didn't lend me a loan, they told anyone who has such child and we cannot lend her"(P9).

\section{Seeking peace}

Some of the participants were so tired of the situation, because they have to care for patient for a long time, such as the participants nine, ten and eleven, who had engaging in caring more than four months in the hospital, and there was no optimal prognosis in the future. Therefore, the caregivers tried to escape 
these situations to calm selves and somehow overcome the problems. For this purpose they tried to be "rely on praying" and "drain the feelings", which had about 42 codes and statements.

\section{Rely on praying}

The participants were relying on religions values, therefore, stated this by words such as "resorting to prayer", "hope to God", "giving Alms", and "appealing to Imams". They try to peace herself and know the event as the "Divine providence". One of the participants in interview 8 said "Until the morning prayer, I was awake and one of her (patient) sisters who was single was by my side and we were crying and crying and praying, until the morning we had only remembered Imam Reza and all our vows were in the way of Imam Reza". Another caregiver declared "Our religious beliefs are very high and I always say that the doctors are the means, and only God can do it, on his own, and he can also heal my wife and I have prayed for him and many vows that if he should heal, to spend the rest of my life with" (P6). Some participants took arbitrary fasting, one of them indicated "I was fasting and every hour of the night I woke up praying for God to save him (patient)" (P3).

\section{Drain the feelings}

Drain the feelings stated in 13 statement as a way to calming her/himself. It indicated by "show kindness", "happy with the patient", and "crying". Participant 1 said "because I love my spouse, very much, I can't and don't want to hear anything that disappoints me". Other participant show her affection to patient and said "she understands all my words. The last time I took a bath, I was very upset and cried for her, and she shook her mouth, thought something was saying, I approached my face and said something, kissed me, and his face was in a state that seemed to thank me"(P3). Three of the participants hoped to end up the situation, one of them who was the nephew of the patient said "I like he would get well sooner or her daughters take her; I'd love to get out of here sooner because I'm really tired, it is close to the school time and haven't done any of my school works" (P2).

\section{3. imposed therapeutic duties}

Approximately all the participants have accepted some imposed therapeutic roles and actions and tried to learn and apply them as appropriate as possible, 107 meaning statements have been extracted. For this purpose four subthemes has been emerged, including: "Relationship with staff", "Information gap", "Assess patient status", "Doing holistic Caring”.

\section{Relationship with staff}

This subtheme extracted from 22 codes and statements, and the participants had variant communicating with staff, from friendship to fear and worries about staff behaviors. Mostly expressed their satisfaction of personnel, because their allowance to be at the bedside of patients and participate in the care. Participant 8 noted that " the staff were really good and allowed me to stay with my wife and read the Koran while they were in the ICU, and explained a lot to us", other participant declared "The nurses are great, I have a good relationship with them; the crews are not bad either and they are good" (P5). However 
some caregivers have no enough satisfaction of staff because they did not do the care of patients properly for example participant 1 said "my husband needs to have a catheter replaced early because her catheter is blocked early, but the nurses change it later and say we're tired so much.... when my husband is bad they wailing about what happened to him... (for this), I feel sad, but I don't say anything".

\section{Information gap}

Six of participants did not know the causes of injury/trauma, some supposed the violence is the reason of damage, other said the patient felled, in this line, they heard controversies and somehow opposite words from health-care workers. Participant 4 said" They said God knows what is going on. The nurses said we would neither hope nor despair, but it could be paralyzed. One of the doctors said he (patient) was in another universe (I'm not sure I'm right), in the name of the vegetative world and said that his alertness was five and that it might stay that way for the rest of his life, we would all be very upset". Other caregiver represented "His doctor has said it will take time to heal and may not heal at all" (P2). Some of them stated they do not know how to care patients after discharge.

\section{Assess patient status}

The caregivers tried to understand the meanings of consciousness and assess them in various times. All of them know, what the meanings of Glasgow coma scale number is, and hoped to raise. Participant six said "No one has explained to us and they just say it's good to go up and the highest number is 15 and they say if it reaches 9 or 10, it's really a big number for me because I don't have anyone and my husband is a shadow of my head and my son (a proverb means a supporter)". Participant seven also noted "When it (the consciousness) was 4, we were frustrated and upset, But as it went up, we were hopeful".

\section{Doing holistic Caring}

In 52 statement the participants declared their caring measures and their readiness for long term care with patients. Two of the participants who were sister (P11) and mother (P10), said they are ready to "scarify herself for the patient". Participant three, in response to the question of "how long do you want to continue care?", answered "I'll continue to the last point as long as it takes", the caregivers tried to address all the needs of patients from basic to advanced, in this regards participant 12 , who is a women with 69 years old and is the mother of patient, said "First I come (to ward), wash his hands and face and rub olive oil all over her body, clean her teeth, gavage her and give him pills, then do suction and bath". Participant 11 announced that she carryout the advanced cares of the patient "We do suction, change her oxygen tube, clean her mouth, and give her food and medicine. We've done whatever the doctors said".

\section{4. preserve connection}

About this theme, we identify 88 meaningful statements and the participants tried to hold their connection to patient and maintain hope, however, they affected by some happenings. In this aspect we extracted two subthemes of "Swing hope-disappointment", "Communicate to patient ". 


\section{Swing hope-disappointment}

Some participants took hope by observing the improving signs. This mostly needed time to happening and create a more hope to future. The caregiver in interview 6 said "When my son spoke the name of Imam Reza and my wife was shaking, both my son and I were hopeful, and that is a great and good memory for me, and I am getting more and more hopeful". In this regard, the participant 10 said that she get hope from God "I hoped and said it was going to be good and although (they=staff) did not gave hope, I was hoping for it, myself and now I have more hope and trust in God and I think it's going to be fine". However, sometimes disappointment would be occurred because of "staff statement of illness of patient", "seeing similar patients", and "having no movement or signs". Caregiver in interview 5 said "-First we were hoping and thinking, my mother would be fine but when we went to ICU, we were disappointed. Another patient was similar to my mother in the ICU and we met with her companions and went to the ward before my mother, and later when we asked, she was died". Participant 11 also complained and said "- I was expecting the doctors to give hope, but the doctor disappointed us so much. Once we went to another doctor's office and he hoped for us and even wrote down medications that, his doctor hadn't written for him and we provided the drugs by my families in other country".

\section{Communicate to patient}

The caregivers struggle to communicate to patients by all the approaches, participant 1 said the patient look her while she is speaking, another one used hands-free with familiar voice to patient (P2), the mother of patient in interview 12 said" -I asked one of the staff who was there, if my son was listening to me? He said ... he was listening and explained to me that he was like a child that he talks to and hears and understands but cannot speak. I thought maybe he would understand. When I told her that I was your mother and if you could shake your hand or your foot, she shook her hand and I had a special feeling at that moment, saying, thank God, she understands". Some showed empathic feeling for example in interview 4 "I liked to be instead of her in bed, and my sister would be fine". The caregiver in interviewee 7 mentioned the memories to patient and take response "Sometimes when I tell her memories of the past, she smiles and shakes hands and feet".

\section{Unheard sounds}

The caregivers had some expectations and complains that want to be heard, these are stated in 41 remarkable statement. Participants 11 complained that the hospital do not prepare good accommodation for them, "They do not give food to the caregivers, while they are very tired and have to feed... There is no rest here, and we need a refrigerator and even a trash near my brother's bed. Patients like (my patient) should be in a separate room, because noise pollution is so harmful ..., My mother wanted to stay the night several times but because she was with other patients families that are man, she is not comfortable to sleep in the room and she was not even fit and unfortunately her chair that were, not folded (it is broken)". Participant 9 complain about the crowding of the ward and said "his lungs are infected and there is very infected people here because the room has four patients and each patient has a few visitors to the room. It is not suitable for patients. If the rooms be single, they will heal sooner... -the doctor who 
doesn't have time and I don't see him. Just I went to the office one day and waited for several hours to see him. The nurses say take her (patient) home, and I tell by what means? Here they (nurses) get a (blood) pressure, they dispense ampoules around the umbilical so that their blood doesn't clot and (do) suction. How do I do this at home?". Some participants such as five and six expected to take a clear response from staff about patient situations, and the caregiver three requested the bathroom and floor should be cleaned".

\section{Discussion}

This study was conducted with purpose of, exploring the Iranian care-givers experiences of caring for PSV patients following $\mathrm{TBI}$, in a qualitative study. This study was conducted by interviewing of caregivers in main center of trauma in Kermanshah-west of Iran. The data showed that this caregivers were suffered and tolerated tensions including physical, and psychological and confronted with some familial crises such as diverse, unemployment and economic issues. In a cross-sectional study by Yousefzadeh-Chabok et al. (2018) in Guilan-Iran, the caregivers of PVS patients had some psychological problems consisting depression, anxiety, phobia, somatoform, obsessive-compulsive and paranoid(26). Other study in Italy, verified many physical and psychological problems in these caregivers(27) and Chiambretto et al. declared that PVS caregivers are affected continually with a prolonged grief(28). Gudarzi et al. in a qualitative research, represented that the Iranian caregivers of PVS patients suffered from some physical and psychological injuries such as herniated disk, knee and arm pain, malnutrition, sexual disorder, sever fatigue and insomnia(18). The results are congruent with our study. The possible causes of the physical and psychological problems in these caregivers are related to the thoughts of caregivers about possible death of the patient(29), and feelings of uncertainty(30). In additions, against some literatures that family members should be cared for and address their needs(31), in Iran, the caregivers are neglected and have no any attention to them(32). In this regard, another study in China showed that the psychological interventions reduces anxiety and enhance coping power of PVS caregivers(33). We believe the caregivers of PVS patients should be visited periodically by clinicians, and underwent some psychological and physical supports in the hospitals.

The participants of the study tried to smooth her/himself with praying and changings the feelings toward having hope and think positively. These measures maybe help them to reach a coping with issue. Goudarzi et al. (2018), in a qualitative study on PVS patients, extracted the concept of "lasting hope" with subthemes of "positive thinking about patient recovery" and "hopeful care", meaning that the caregivers tried to hold their hope and continue the care and avoid stimulators that threatened their thoughts and hope. Furthermore, for maintaining hope they relied on spirituality(19). Other studies revealed the role of believes to spirituality and religion on coping of caregivers of cancer(34) and Alzheimer(35) patients. These results are accordance with our findings. Spirituality is one of the main domains of human-being, and attending to it could enhance self-awareness and comprehend meanings of live that connect individuals to transcendent power or God(34), hence, they feel an "inner peace"(36). Iranian PVS caregivers seek meaning in care of patients and try to feel that their works are in line with spiritual and 
religious beliefs, therefore, God gives their rewards, and they could reach coping easily with endure the difficulties of caregiving(37). This topic has a root in Iranian culture that demanded more studies.

The participants of the PVS did some therapeutic duties and tried to engage in caring measures with doing some specific cares such as changes position and suction, also they had information gap about cares, continually assess the patient, and attempted to do a holistic care. In a qualitative research by Cipolletta et al. the caregivers of PVS know themselves as one who comprehend and answer all the needs of their patients, they had not complete trust to healthcare workers and need clear information(38). In addition, other study in Iran, showed that these caregivers have a voracity for education, and consider all the resources for this purpose. Because they had fear of after discharge and doing imposed cares such as feeding, change position, change bedsheets and take medications(39). It seems another factors affecting this situation are nursing shortage and workloads in Iranian hospitals that induce nurses using caregivers to assist patients(40), in this regard, some believed that nurses should educate caregivers scrutiny(17), for doing a comprehensive care(18).

The caregivers have some complaints and declared that their words are not heard, most of them was related to accommodation and no dedicating enough time by physicians and nurses. Others demanded hope from the healthcare staff. The governmental hospitals of Iran are lake of appropriate accommodations, so they are suffering for caregivers(32). they will be frustrated of being in hospital and cannot participate in care giving in a good manner(41). In a study by Ashrafian et al. on "unmet needs of caregivers" in Iran. The highest needs were related to information and visiting physician and nurse staff as quick as possible(42). Because there is insufficient homecare services in Iran, the teaching and supporting roles of nurses and physicians for PVS caregiver is more prominent(37). These caregivers inhabit for a long period in the hospital, so, it is suggested to provide the required services and the staff reduce their suffering by offering compassionate and good relationship, and assign times for answering their questions.

This study had some advantages and maybe disadvantages; the researchers of the study were the physician and clinical staff of patients, therefore they had more understandings of the patients and caregivers condition. However, most of caregivers were female, and due to their tiredness the interviews were somehow short, which may be considered as shortcomings.

\section{Conclusion}

This qualitative study was done on caregivers' experiences of caring for persistent vegetative state of patients with TBI. The patients were hospitalized in the biggest trauma center in west of Iran. The caregivers experienced some tensions, physical and psychological injuries, and some familial crises were happened. Because the caregivers cared for long-term (at least one month), they wished to liberate by praying and drain their feelings. Furthermore, they did some therapeutic duties and tried to address all the patients' needs and assess patients' signs, daily. However, they had an information gap and wanted to obtain them by relationship with staff. The caregivers communicated with patients and hold hope to 
recovering the patient. They were complained of accommodations and lack of staff visits. Regarding the results of this study, it is recommended to address all of the concerns of these caregivers and do additional supportive measures.

\section{Abbreviations}

TBI

traumatic brain injury

PSV

persistent vegetative state

\section{Declarations}

\section{Ethics approval and consent to participate}

The study was approved by research ethics committee of Kermanshah University of medical sciences

\section{Consent for publication}

All the authors and the Kermanshah University of Medical Sciences consented to publish the study in your journal

\section{Availability of data and material}

Data available by contacting the corresponding author

\section{Competing interests}

The authors declare there are no competing interests

\section{Funding}

The study was funded by Kermanshah University of Medical Sciences

\section{Authors' contributions}

EA and $A A$, and AAR contributed in designing the study, EA and AAR collected the data, and analyzed by EA and AA. The final report and article were written by AA, HR and EA, and the paper were read and approved by all the authors

\section{Acknowledgment}


This study is the results of an approved project by student research committee of research deputy of Kermanshah University of medical sciences. The ethics research committee of the university confirmed the ethical considerations. We are grateful the officials of the research deputy and Taleghani hospital and the caregivers who participated in this study.

\section{References}

(1) Nguyen R, Fiest KM, McChesney J, Kwon CS, Jette N, Frolkis AD, et al. The international incidence of traumatic brain injury: a systematic review and meta-analysis. Canadian journal of neurological sciences 2016;43(6):774-85.

(2) Li M, Zhao Z, Yu G, Zhang J. Epidemiology of traumatic brain injury over the world: a systematic review. General medicine: open access 2016;4(5):e275.

(3) Saatian M, Ahmadpoor J, Mohammadi Y, Mazloumi E. Epidemiology and pattern of traumatic brain injury in a developing country regional trauma center. Bulletin of Emergency \& Trauma 2018;6(1):45.

(4) Tang Q, Lei J, Gao G, Feng J, Mao Q, Jiang J. Prevalence of persistent vegetative state in patients with severe traumatic brain injury and its trend during the past four decades: A meta-analysis. NeuroRehabilitation 2017;40(1):23-31.

(5) Adams ZM, Fins JJ. The historical origins of the vegetative state: Received wisdom and the utility of the text. Journal of the History of the Neurosciences 2017;26(2):140-53.

(6) Real RG, Veser S, Erlbeck H, Risetti M, Vogel D, M++ller F, et al. Information processing in patients in vegetative and minimally conscious states. Clinical Neurophysiology 2016;127(2):1395-402.

(7) Owen AM, Schiff ND, Laureys S. The assessment of conscious awareness in the vegetative state. The Neurology of Conciousness. Elsevier; 2016. p. 155-66.

(8) Dilling D. Diagnostic criteria for persistent vegetative state. AMA Journal of Ethics 2007;9(5):35961.

(9) Georgiopoulos M, Katsakiori P, Kefalopoulou Z, Ellul J, Chroni E, Constantoyannis C. Vegetative state and minimally conscious state: a review of the therapeutic interventions. Stereotactic and functional neurosurgery 2010;88(4):199-207. 
(10) Puggina ACG, Da Silva MJIP, Schnakers C, Laureys S. Nursing care of patients with disorders of consciousness. Journal of Neuroscience Nursing 2012;44(5):260-70.

(11) Payne K, Taylor RM, Stocking C, Sachs GA. Physicians' attitudes about the care of patients in the persistent vegetative state: a national survey. Annals of internal medicine 1996;125(2):104-10.

(12) Ramezani F, Sobhani M. Euthanasia from Iran law and Islamic legislation perspective. International Journal of Human Rights and Constitutional Studies 2016;4(2):153-65.

(13) Estraneo A, Moretta P, Loreto V, Lanzillo B, Santoro L, Trojano L. Late recovery after traumatic, anoxic, or hemorrhagic long-lasting vegetative state. Neurology 2010;75(3):239-45.

(14) Corallo F, Bonanno L, Lo Buono V, De Salvo S, Rifici C, Bramanti P, et al. Psychological distress of family members of vegetative and minimally conscious state patients. Acta Medica Mediterranea 2015;31(2):297-302.

(15) Soeterik SM, Connolly S, Playford ED, Duport S, Riazi A. The psychological impact of prolonged disorders of consciousness on caregivers: a systematic review of quantitative studies. Clinical rehabilitation 2017;31(10):1374-85.

(16) Ramezani M, Mohammadi M, Beigmohammadi MT, Abtahi H, Ahmadi M, Safavi E. Admission and Discharge from ICU: Do We Have any Protocol? Archives of Anesthesiology and Critical Care 2015;1(4):141-3.

(17) Noohi E, Peyrovi H, Goghary ZI, Kazemi M. Perception of social support among family caregivers of vegetative patients: A qualitative study. Consciousness and Cognition 2016;41:150-8.

(18) Goudarzi F, Abedi H, Zarea K, Ahmadi F. Multiple victims: The result of caring patients in vegetative state. Iranian Red Crescent Medical Journal 2015;17(6).

(19) Goudarzi F, Abedi H, Zarea K, Ahmadi F, Hosseinigolafshani SZ. The resilient care of patients with vegetative state at home: a grounded theory. Journal of caring sciences 2018;7(3):163.

(20) Mihas P. Qualitative data analysis. Oxford Research Encyclopedia of Education. 2019.

(21) Jackson C, Vaughan DR, Brown L. Discovering lived experiences through descriptive phenomenology. International Journal of Contemporary Hospitality Management 2018;30(11):3309-25.

(22) Etikan I, Musa SA, Alkassim RS. Comparison of convenience sampling and purposive sampling. American journal of theoretical and applied statistics 2016;5(1):1-4.

(23) Saunders B, Sim J, Kingstone T, Baker S, Waterfield J, Bartlam B, et al. Saturation in qualitative research: exploring its conceptualization and operationalization. Quality \& quantity 2018;52(4):1893-907. 
(24) Morrow R, Rodriguez A, King N. ColaizziGÇÖs descriptive phenomenological method. The psychologist 2015;28(8):643-4.

(25) Shenton AK. Strategies for ensuring trustworthiness in qualitative research projects. Education for information 2004;22(2):63-75.

(26) Yousefzadeh-Chabok S, Emamhadi M, Alijani B, Cheragh Sepehr M, Khodadadi-Hassankiadeh N. Psychopathological Symptoms in Caregivers of Patients With Vegetative State. Caspian Journal of Neurological Sciences 2018;4(2):57-63.

(27) Pagani M, Giovannetti AM, Covelli V, Sattin D, Raggi A, Leonardi M. Physical and mental health, anxiety and depressive symptoms in caregivers of patients in vegetative state and minimally conscious state. Clinical psychology \& psychotherapy 2014;21(5):420-6.

(28) Chiambretto P, Moroni L, Guarnerio C, Bertolotti G, Prigerson HG. Prolonged grief and depression in caregivers of patients in vegetative state. Brain Injury 2010;24(4):581-8.

(29) Chiambretto P, Ferrario SR, Zotti AM. Patients in a persistent vegetative state: caregiver attitudes and reactions. Acta Neurologica Scandinavica 2001;104(6):364-8.

(30) Shin JY, Lim J, Shin DW, Kim SY, Yang H, Cho J, et al. Underestimated caregiver burden by cancer patients and its association with quality of life, depression and anxiety among caregivers. European journal of cancer care 2018;27(2):e12814.

(31) Kleinpell RM, Powers MJ. Needs of family members of intensive care unit patients. Applied nursing research 1992;5(1):2-8.

(32) Akbari M, Alavi M, Irajpour A, Maghsoudi J. Challenges of family caregivers of patients with mental disorders in Iran: A narrative review. Iranian journal of nursing and midwifery research 2018;23(5):329.

(33) Li YH, Xu ZP. Psychological crisis intervention for the family members of patients in a vegetative state. Clinics 2012;67(4):341-5.

(34) Borjalilu S, Shahidi S, Mazaheri MA, Emami AH. Spiritual care training for mothers of children with cancer: effects on quality of care and mental health of caregivers. Asian Pac J Cancer Prev 2016;17(2):545-52.

(35) Eifert EK. Religious Coping While Providing Care for Someone with Alzheimer's Disease. Perspectives on Science and Christian Faith 2017;69(4):217-8.

(36) Nemati S, Rassouli M, Baghestani AR. The spiritual challenges faced by family caregivers of patients with cancer: A qualitative study. Holistic nursing practice 2017;31(2):110-7. 
(37) Imani-Goghary Z, Noohi E, Peyrovi H, Kazemi M. Exploring the role of spirituality in coping process of family caregivers of patients in vegetative state. Journal of Advances in Medicine and Medical Research 2016;1-11.

(38) Cipolletta S, Pasi M, Avesani R. Vita tua, mors mea: the experience of family caregivers of patients in a vegetative state. Journal of health psychology 2016;21(7):1197-206.

(39) Goudarzi F, Abedi HA, Zarea K, Ahmadinejad F. Caring experiences and challenges of families with patients in vegetative state. Journal of clinical nursing and midwifery 2015;3.

(40) Abbaszadeh A, Abdi A. Nursing shortage challenge: A serious threat for the health system: A review study. Community Health Journal 2015;9(1):37-47.

(41) Bahrami M, Etemadifar S, Shahriari M, Farsani AK. Caregiver burden among Iranian heart failure family caregivers: A descriptive, exploratory, qualitative study. Iranian journal of nursing and midwifery research 2014;19(1):56.

(42) Ashrafian S, Feizollahzadeh H, Rahmani A, Davoodi A. The Unmet Needs of the Family Caregivers of Patients with Cancer Visiting a Referral Hospital in Iran. Asia-Pacific journal of oncology nursing 2018;5(3):342.

\section{Tables}

Table 1: characteristics of the participants who recruited in the study

\begin{tabular}{|l|l|l|l|l|l|l|}
\hline $\begin{array}{l}\text { Participant } \\
\text { number }\end{array}$ & Gender & $\begin{array}{l}\text { Age } \\
\text { (year) }\end{array}$ & $\begin{array}{l}\text { Type of family } \\
\text { relation }\end{array}$ & $\begin{array}{l}\text { Time of } \\
\text { caring } \\
\text { (day) }\end{array}$ & $\begin{array}{l}\text { Patient time } \\
\text { hospitalization } \\
\text { (day) }\end{array}$ & $\begin{array}{l}\text { Time } \\
\text { interview } \\
\text { (minute) }\end{array}$ \\
\hline P1 & female & 31 & wife & 90 & 130 & 18 \\
\hline P2 & female & 17 & nephew & 60 & 127 & 28 \\
\hline P3 & female & 33 & brother's wife & 50 & 120 & 31 \\
\hline P4 & male & 32 & brother & 100 & 120 & 21 \\
\hline P5 & female & 16 & daughter & 160 & 220 & 23 \\
\hline P6 & female & 29 & wife & 30 & 30 & 20 \\
\hline P7 & female & 52 & mother & 90 & 90 & 35 \\
\hline P8 & female & 28 & wife & 100 & 100 & 33 \\
\hline P9 & female & 59 & mother & 50 & 130 & 48 \\
\hline P10 & female & 63 & mother & 66 & 190 & 43 \\
\hline P11 & female & 22 & sister & 80 & 154 & 23 \\
\hline P12 & female & 69 & mother & & \\
\hline
\end{tabular}




\begin{tabular}{|l|l|}
\hline theme & subtheme \\
\hline \multirow{2}{*}{ falling into tensions } & Caregiver injuries \\
\cline { 2 - 2 } & Familial crises \\
\hline \multirow{3}{*}{ Seeking peace } & Rely on praying \\
\cline { 2 - 2 } & Drain the feelings \\
\hline \multirow{3}{*}{ imposed therapeutic duties } & Relationship with staff \\
\cline { 2 - 2 } & Information gap \\
\cline { 2 - 2 } & Assess patient status \\
\cline { 2 - 2 } & Doing holistic caring \\
\hline preserve connection & Swing hope-disappointment \\
\cline { 2 - 2 } & Communicate to patient \\
\hline Unheard sounds & Unheard sounds \\
\hline
\end{tabular}

